\title{
Rheumatoid factor tests in the diagnosis and prediction of rheumatoid arthritis
}

\author{
D J WALKER, ${ }^{1}$ J D POUND, ${ }^{2}$ I D GRIFFITHS, ${ }^{1}$ AND R J POWELL ${ }^{2}$ \\ From the ${ }^{1}$ Department of Rheumatology, Royal Victoria Infirmary, Newcastle upon Tyne; and the ${ }^{2}$ Department \\ of Immunology, University Hospital, Nottingham
}

SUMMARY Four assays of rheumatoid factor (RF) have been measured on serum from 213 individuals from 13 families containing at least two sufferers from classical or definite rheumatoid arthritis (RA). Families were not uniformly RF positive or negative, and there was no evidence that non-RA RF positivity was inherited. Four individuals developed definite RA over a two year period, showing that the family members were at increased risk of RA. IgG RF and latex RF assays predicted the RA in the four cases. An association of RF positivity in RA with DR4 was observed, but this may be related to disease severity.

Key words: HLA, inheritance, family study.

The role of rheumatoid factor (RF) in the aetiopathogenesis of $\mathrm{RA}$ remains unclear. It is known that RFs may be present before the onset of clinical disease, ${ }^{1}$ but more usually RFs are not detectable in serum until several months after onset, and some patients with clinical RA remain persistently seronegative by conventional RF tests. Evidence that seropositive and seronegative RA may be different diseases is suggested by a recent report showing that each has different strengths of association with different HLA antigens. ${ }^{2}$ Different patterns of radiological involvement in seropositive and seronegative RA have also been reported. ${ }^{3}$ The observation that seropositive RA is more familial ${ }^{4}$ might suggest that RF itself is inherited. RF positivity, however, is associated with more severe and more active disease, and the familial nature of RF positivity in RA may be related solely to disease severity. Little is known of the predictive value of RF tests for RA, but in one population based study three individuals developing RA had previously been RF positive compared with one who had been seronegative. ${ }^{5} \mathrm{~A}$ predictive role for $\mathrm{RF}$ was also found by Aho et al. ${ }^{1}$ A follow up study of false positive individuals has therefore been performed.

Accepted for publication 29 January 1986.

Correspondence to Dr D J Walker, Department of Rheumatology,

Queen Victoria Road, Royal Victoria Infirmary, Newcastle upon Tyne NE1 4LP.

\section{Patients and methods}

Four assays for RF were performed on serum from 213 individuals from 13 families selected for containing at least two individuals suffering from classical or definite RA by American Rheumatism Association (ARA) criteria. ${ }^{6}$ Thirty seven individuals had classical or definite RA, 13 had probable RA, and five were classified as having previous RA. ${ }^{7}$

The four RF tests assayed were: $(a)$ The RAHA test (Fujizoki pharmaceutical), which uses rabbit IgG passively bound to sheep red blood cells (RBC). A titre of 1/40 was taken as the lowest positive value. (b) The IgG RF ratio. This test detects IgG antibodies to a human Fc fragment attached to a plastic well. ${ }^{8}$ Labelling was with radioactive anti-IgG, and quantification was by comparison with a negative control. A ratio of 2.5 was taken as the lowest positive value. (c) The sheep cell agglutination test (SCAT), which uses rabbit IgG actively bound to sheep RBC. A titre of $1 / 32$ was taken as the lowest positive value. $(d)$ The latex 0 fixation test (Hyland), which uses human IgG passively bound to latex particles.

Comparisons for associations between the four tests were made using the $\chi^{2}$ test, and a similar method was used for comparisons of RF titres. Sensitivity and specificity were calculated by the formula recommended by Lawrence. ${ }^{9}$ 
Table 1 Comparison of positive rheumatoid factor test results and clinical diagnosis

\begin{tabular}{lcccccc}
\hline & Total & RAHA & IgG RF & SCAT & Latex & Any test \\
\hline Classical and definite RA & 37 & $27(73 \%)$ & $27(73 \%)$ & $17(46 \%)$ & $19(51 \%)$ & $33(89 \%)$ \\
Probable RA & 13 & $1(8 \%)$ & $1(8 \%)$ & $1(8 \%)$ & $3(23 \%)$ & $3(23 \%)$ \\
Previous RA & 5 & 0 & 0 & 0 & $1(20 \%)$ & $1(20 \%)$ \\
Non-RA & 158 & $2(1 \%)$ & $13(8 \%)$ & $7(4 \%)$ & $9(6 \%)$ & $17(11 \%)$ \\
Specificity (\%)* & & 84 & 60 & 57 & 49 & 53 \\
Sensitivity (\%)* & & 71 & 65 & 41 & 44 & 75 \\
\hline
\end{tabular}

"Calculated by the method of Lawrence. ${ }^{9}$

$\mathrm{RF}$ positivity is one of the ARA criteria for diagnosis of RA. The RAHA test was used for this purpose as it was the routine test available. Rheumatoid factor positivity frequently differentiates between the diagnosis of definite and classical RA and hence these are grouped together. In only one case did an isolated positive RAHA make the difference between probable and definite RA. Any bias towards RAHA was therefore small.

Nineteen individuals were rheumatoid factor positive by at least one test in the absence of definite disease. A follow up study of these individuals has been carried out with the nearest unaffected same sex sibling as a control. Where this was not possible a control matched for age and sex was taken from the same family.

All families were approached through the index cases to see if any other individuals had developed problems with their joints. Anyone in this category was seen and assessed clinically.

\section{Results}

\section{RHEUMATOID FACTOR TESTS}

A comparison of the four rheumatoid factor tests with clinical diagnosis is summarised in Table 1.

Calculations of the specificity and sensitivity show that in this population RAHA proved more specific and more sensitive than the other tests. IgG rheumatoid factor was more specific and sensitive than SCAT and the latex fixation test. Probable RA was not usually associated with the presence of

Table 2 Association of $R F$ positivity with $H L A-D R 4$

\begin{tabular}{|c|c|c|c|c|c|}
\hline \multirow[t]{2}{*}{$R F$ test } & \multicolumn{2}{|c|}{$R F$ positive } & \multicolumn{2}{|c|}{$R F$ negative } & \multirow{2}{*}{$\begin{array}{l}\text { Comparison } \\
\text { seropositivel } \\
\text { negative for } D R 4\end{array}$} \\
\hline & $D R 4^{+}$ & $D R 4^{-}$ & $D R 4^{+}$ & $D R 4^{-}$ & \\
\hline $\begin{array}{l}\text { RAHA } \\
\text { IgG RF } \\
\text { Any RF test }\end{array}$ & $\begin{array}{l}26 \\
34 \\
46\end{array}$ & $\begin{array}{l}4 \\
7 \\
8\end{array}$ & $\begin{array}{r}119 \\
111 \\
99\end{array}$ & $\begin{array}{l}64 \\
61 \\
60\end{array}$ & $\begin{array}{l}p<0.02 \text { by } \chi^{2} \text { test } \\
p<0.05 \text { by } \chi^{2} \text { test } \\
p<0.01 \text { by } \chi^{2} \text { test }\end{array}$ \\
\hline
\end{tabular}

rheumatoid factor by any test. Performing all four tests and accepting any positive test as significant adds to the sensitivity at the expense of specificity.

The 10 seronegative RA patients by RAHA occurred in seven families, the $10 \mathrm{IgG}$ seronegative RA patients occurred in six families, the 20 SCAT negative RA patients were from 10 families, and the 18 latex negative RA patients were from 11 families. The four RA sufferers negative by all four tests were from four different families. The patients with RF negative RA were therefore spread through several families, and families are not uniformly RF positive or RF negative.

Table 2 shows the association of positive RF tests with HLA-DR4. If, however, individuals with classical and definite RA were excluded leaving only the false positives (Table 3 ) then no association was shown with DR4. HLA-DR4 was therefore associated with rheumatoid disease rather than RF positivity. No association was found with any other DR antigens.

Fig. 1 shows the relation of RAHA titre and IgG RF index to the inheritance of HLA-DR4 (homozygous, heterozygous, and non-DR4) in individuals suffering from classical and definite RA. There were two individuals in whom it was unclear whether they were homozygous DR-4, or 4, blank and these have been excluded from this figure. There was no significant difference in the titre of RF positivity between these groups. Neither HLA-DR4 nor

Table 3 Association of non-RA RF positivity with HLA-DR4

\begin{tabular}{|c|c|c|c|c|c|}
\hline \multirow[t]{2}{*}{$R F$ test } & \multicolumn{2}{|c|}{ False positives } & \multicolumn{2}{|c|}{ True negatives } & \multirow{2}{*}{$\begin{array}{l}\text { Comparison of } \\
\text { false positives } \\
\text { and true negatives } \\
\text { for DR4 }\end{array}$} \\
\hline & $D R 4^{+}$ & $D R 4^{-}$ & $D R 4^{+}$ & $D R 4^{-}$ & \\
\hline $\begin{array}{l}\text { RAHA } \\
\text { IgG RF } \\
\text { Any RF test }\end{array}$ & $\begin{array}{r}1 \\
10 \\
15\end{array}$ & $\begin{array}{l}1 \\
3 \\
4\end{array}$ & $\begin{array}{l}99 \\
90 \\
84\end{array}$ & $\begin{array}{l}57 \\
55 \\
55\end{array}$ & $\begin{array}{l}\mathrm{p}=N S \text { by } \chi^{2} \text { test } \\
\mathrm{p}=\mathrm{NS} \text { by } \chi^{2} \text { test } \\
\mathrm{p}=\mathrm{NS} \text { by } \chi^{2} \text { test }\end{array}$ \\
\hline
\end{tabular}




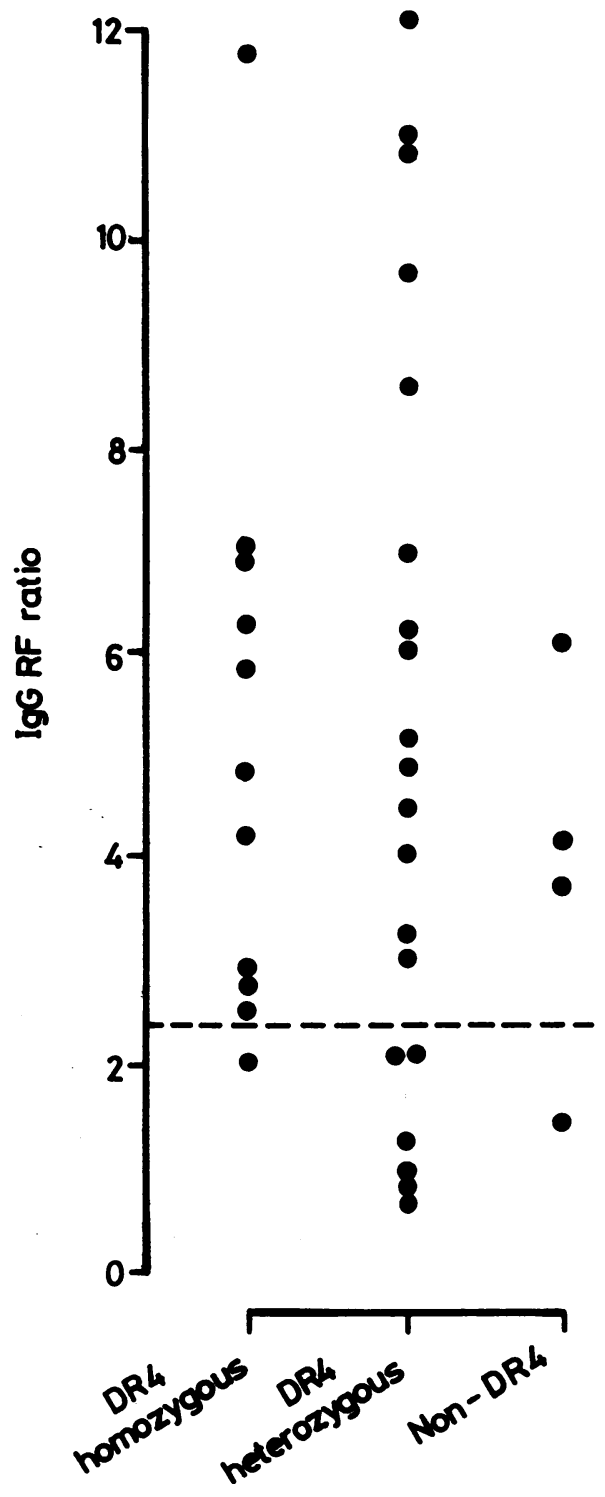

homozygosity for HLA-DR4 were associated with higher titre seropositivity, although for IgG RF there is a trend towards more RF the greater the number of DR4 antigens inherited.

Table 4 shows the prevalence of RA and positive RF tests in index cases and their relatives. This shows that the prevalence of RA and positive RF tests fell with increasing degree of relativity to the proband, and the $>2$ degree relatives have similar prevalence of disease to the non-blood relatives. The association of non-RA (false) positive RF tests

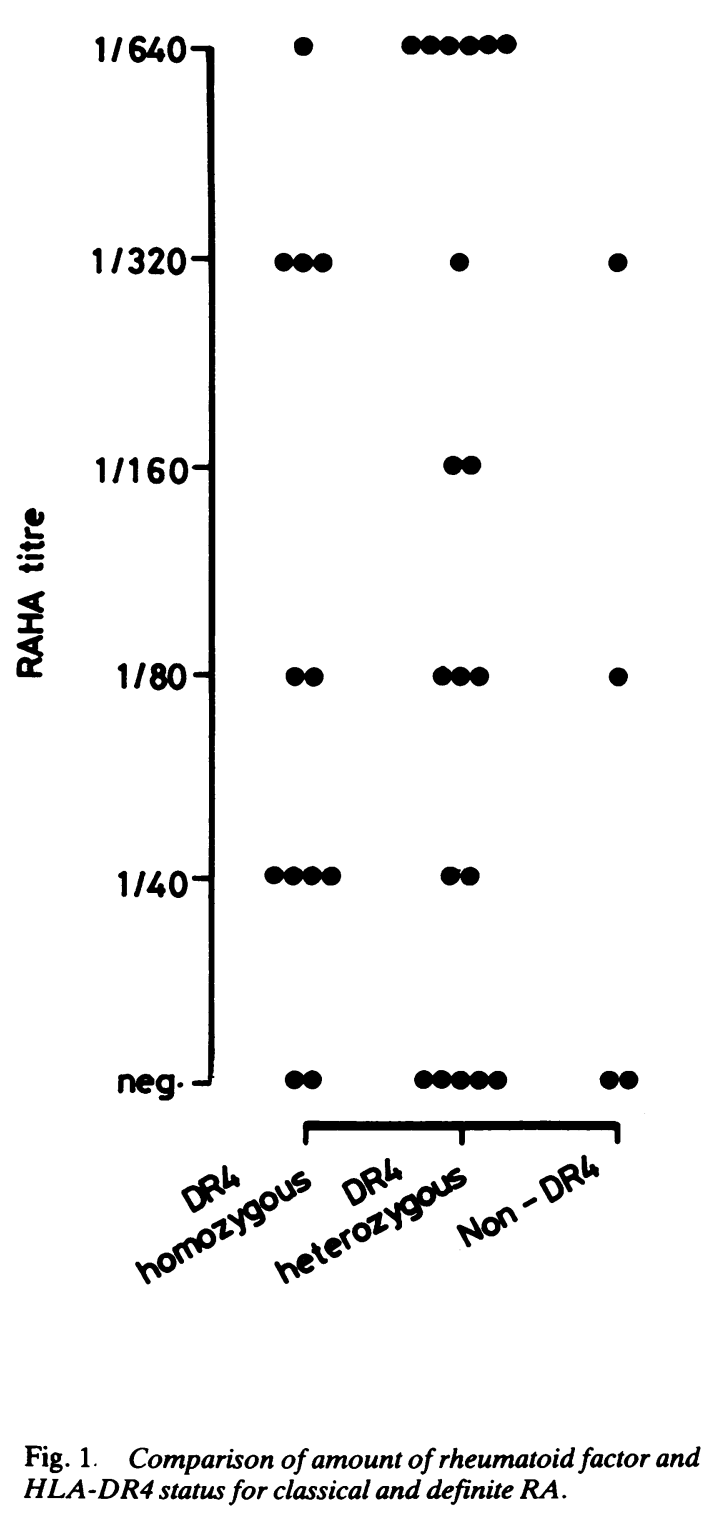

and degree of relativity to the proband is shown in Table 5 . The percentage positivity was variable and $\omega$ showed no trend.

Table 6 shows the classical and definite RA cases $\stackrel{\circ}{\subset}$ and their seropositivity by degree of relativity to the $\mathbb{\Phi}$ proband. Distant relatives showed a trend towards ? less seropositivity, but this was well short of statistical significance and may be accounted for by the decreasing severity of the disease.

These results again imply that RF positivity was $\stackrel{\mathbb{D}}{\varrho}$ not inherited per se, but only as part of RA. 
Table 4 Prevalence of rheumatoid factors in the families by degree of relativity to the proband

\begin{tabular}{|c|c|c|c|c|c|c|c|c|c|}
\hline Relation & Total & $\begin{array}{l}\text { Classical and } \\
\text { definite } R A\end{array}$ & $\begin{array}{l}\text { Probable } \\
R A\end{array}$ & $\begin{array}{l}\text { Classical+ } \\
\text { definite+ } \\
\text { probable } \\
R A(\%)\end{array}$ & $\begin{array}{l}\text { RAHA } \\
\text { positive }\end{array}$ & $\begin{array}{l}\lg G \\
\text { positive }\end{array}$ & $\begin{array}{l}\text { SCAT } \\
\text { positive }\end{array}$ & $\begin{array}{l}\text { Latex } \\
\text { positive }\end{array}$ & $\begin{array}{l}\text { Any test } \\
\text { positive }\end{array}$ \\
\hline Proband & 13 & $13(100 \%)$ & 0 & 100 & $11(85 \%)$ & $10(77 \%)$ & $8(62 \%)$ & $8(62 \%)$ & $11(85 \%)$ \\
\hline 1 degree relatives & 60 & $13(22 \%)$ & 6 & 32 & $9(15 \%)$ & $15(25 \%)$ & $10(17 \%)$ & $13(22 \%)$ & $19(32 \%)$ \\
\hline 2 degree relatives & 39 & $5(13 \%)$ & 3 & 21 & $3(8 \%)$ & $5(13 \%)$ & $3(8 \%)$ & $3(8 \%)$ & $8(21 \%)$ \\
\hline$>2$ degree relatives & & $4(6 \%)$ & 2 & 9 & $5(7 \%)$ & $6(9 \%)$ & $2(3 \%)$ & $4(6 \%)$ & $8(12 \%)$ \\
\hline Non-blood relatives & 33 & $2(6 \%)$ & 2 & 12 & $2(6 \%)$ & $5(15 \%)$ & $3(9 \%)$ & $4(12 \%)$ & $6(18 \%)$ \\
\hline
\end{tabular}

Table 5 Prevalence of rheumatoid factor false positives by degree of relativity to proband

\begin{tabular}{lllllll}
\hline Relation & Total & $\begin{array}{l}\text { RAHA } \\
\text { positive }\end{array}$ & $\begin{array}{l}\text { IgG } R F \\
\text { positive }\end{array}$ & $\begin{array}{l}\text { SCAT } \\
\text { positive }\end{array}$ & $\begin{array}{l}\text { Latex } \\
\text { positive }\end{array}$ & $\begin{array}{l}\text { Any test } \\
\text { positive }\end{array}$ \\
\hline 1 degree relatives & 60 & $1(2 \%)$ & $4(7 \%)$ & $2(3 \%)$ & $4(7 \%)$ & $7(12 \%)$ \\
2 degree relatives & 39 & $0(0 \%)$ & $2(5 \%)$ & $2(5 \%)$ & $1(3 \%)$ & $4(10 \%)$ \\
$>2$ degree relatives & 68 & $1(1 \%)$ & $4(6 \%)$ & $1(1 \%)$ & $2(3 \%)$ & $4(6 \%)$ \\
Non-blood relatives & 33 & $0(0 \%)$ & $2(6 \%)$ & $2(6 \%)$ & $3(9 \%)$ & $4(12 \%)$ \\
\hline
\end{tabular}

Table 6 Prevalence of rheumatoid factor positivity in the classical and definite RA group by degree of relativity to the proband

\begin{tabular}{lcccccc}
\hline Relation & Total & $\begin{array}{l}\text { RAHA } \\
\text { positive }\end{array}$ & $\begin{array}{l}\text { IgG RF } \\
\text { positive }\end{array}$ & $\begin{array}{l}\text { SCAT } \\
\text { positive }\end{array}$ & $\begin{array}{l}\text { Latex } \\
\text { positive }\end{array}$ & $\begin{array}{l}\text { Any test } \\
\text { positive }\end{array}$ \\
\hline Proband & 13 & $11(85 \%)$ & $10(77 \%)$ & $8(62 \%)$ & $8(62 \%)$ & $12(92 \%)$ \\
1 degree relatives & 13 & $8(62 \%)$ & $11(85 \%)$ & $7(54 \%)$ & $8(62 \%)$ & $12(92 \%)$ \\
2 degree relatives & 5 & $3(60 \%)$ & $3(60 \%)$ & $1(20 \%)$ & $2(40 \%)$ & $4(80 \%)$ \\
2 degree relatives & 4 & $4(100 \%)$ & $2(50 \%)$ & $1(25 \%)$ & $1(25 \%)$ & $4(100 \%)$ \\
Non-blood relatives & 2 & $1(50 \%)$ & $1(50 \%)$ & $0(0 \%)$ & $0(0 \%)$ & $1(50 \%)$ \\
\hline
\end{tabular}

Table 7 False positive (FP) follow up

\begin{tabular}{|c|c|c|c|c|c|c|c|c|c|c|c|}
\hline & & Total & $\begin{array}{l}\text { No } \\
\text { DR4 }\end{array}$ & $\begin{array}{l}\text { Classical or } \\
\text { definite } R A\end{array}$ & $D R 4^{+}$ & $\begin{array}{l}\text { Probable } \\
\text { RA }\end{array}$ & $D R 4^{+}$ & $\begin{array}{l}\text { Asymptomatic } \\
R F \text { positive }\end{array}$ & $D R 4^{+}$ & $\begin{array}{l}\text { Asymptomatic } \\
R F \text { negative }\end{array}$ & $D R 4^{+\prime}$ \\
\hline \multirow{2}{*}{ IgG RF } & $\{\mathrm{FP}$ & 12 & 9 & 3 & 3 & 0 & - & 5 & 2 & .4 & 4 \\
\hline & Control & 12 & 5 & 0 & - & 1 & 1 & 0 & - & 11 & 4 \\
\hline \multirow{2}{*}{ RAHA } & FP & 2 & 1 & 1 & 1 & 0 & - & 1 & 0 & 0 & - \\
\hline & Control & 2 & 1 & 0 & - & 0 & - & 0 & - & 2 & 1 \\
\hline \multirow{2}{*}{ SCAT } & $\{\mathbf{F P}$ & 8 & 8 & 2 & 2 & 0 & - & 1 & 1 & 5 & 5 \\
\hline & Control & 8 & 5 & 0 & - & 0 & - & 0 & - & 8 & 5 \\
\hline \multirow{2}{*}{ Latex } & $\int \mathbf{F P}$ & 10 & 9 & 3 & 3 & 0 & - & 3 & 3 & 4 & 3 \\
\hline & Control & 10 & 9 & 0 & - & 1 & 1 & 0 & - & 9 & 8 \\
\hline \multirow{2}{*}{ All tests } & $\{\mathbf{F P}$ & 18 & 14 & 3 & 3 & 0 & - & 6 & 3 & 9 & 8 \\
\hline & Control & 18 & 11 & 0 & - & 1 & 1 & 0 & - & 17 & 10 \\
\hline
\end{tabular}

FALSE POSITIVE FOLLOW UP

Nineteen individuals with no evidence of RA were found to be rheumatoid factor positive by at least one test. Eighteen (95\%) of these agreed to follow up. The results of the follow up study are summarised in Table 7. Each test has been considered separately in order to assess the predictive value of each. The one individual who declined to be followed up was seropositive by $\operatorname{IgG}$ rheumatoid factor alone, and while we did not have follow up samples we knew him to be asymptomatic.

Three individuals from this false positive group had developed classical or definite RA. These three cases are summarised in Table 8 . Only one individual from the control group developed symptoms sufficient for a diagnosis of probable RA. These 
Table 8 Follow up of the three cases that developed $R A$

\begin{tabular}{|c|c|c|c|c|c|c|}
\hline & \multicolumn{2}{|l|}{ Case $1^{*}$} & \multicolumn{2}{|l|}{ Case $2^{*}$} & \multicolumn{2}{|l|}{ Case $3^{*}$} \\
\hline & $\begin{array}{l}\text { lst assessment: } \\
\text { asymptomatic }\end{array}$ & $\begin{array}{l}\text { 2nd assessment: } \\
\text { classical } R A\end{array}$ & $\begin{array}{l}\text { Ist assessment: } \\
\text { asymptomatic }\end{array}$ & $\begin{array}{l}\text { 2nd assessment: } \\
\text { classical } R A\end{array}$ & $\begin{array}{l}\text { lst assessment: } \\
\text { asymptomatic }\end{array}$ & $\begin{array}{l}\text { 2nd assessment: } \\
\text { definite } R A\end{array}$ \\
\hline \multicolumn{7}{|l|}{$R F$ tests } \\
\hline RAHA & Negative & $1 / 320$ & Negative & $1 / 160$ & $1 / 80$ & $1 / 640$ \\
\hline IgG RF & 3.03 & $9 / 74$ & $5 \cdot 4$ & 3.98 & $7 / 12$ & $4 \cdot 45$ \\
\hline SCAT & Negative & $1 / 512$ & $1 / 512$ & $1 / 256$ & $1 / 512$ & $1 / 256$ \\
\hline Latex & Positive & Positive & Positive & Positive & Positive & Positive \\
\hline
\end{tabular}

${ }^{*}$ Case 1: interval between assessments six months, $1^{\circ}$ relative to proband; case 2 : interval 24 months, $>2^{\circ}$ relative; case 3 : interval $\vec{\omega}$ 26 months, $1^{\circ}$ relative.

numbers were too small for valid statistical analysis. All three new classical or definite RA individuals remained seropositive, and none of the control group became seropositive. IgG rheumatoid factor and latex identified all new RA cases, SCAT identified two, and RAHA one. Most of those false positive by SCAT had become true negatives (five out of six). The numbers developing RA over two years if they remained RF positive were: IgG RF 3/8; latex $3 / 6$; RAHA $1 / 2$; SCAT $2 / 3$. Persistently positive results were therefore more predictive of RA. It is interesting that two of the three to develop RA had higher serum IgG levels before the disease than after. A further three individuals false positive for IgG rheumatoid factor or latex had become SCAT positive at follow up, yet they remained asymptomatic. These family members require further follow up. The DR4 status of the different groups is also included in Table 7. The three groups - those developing RA; those remaining false positive; and those becoming RF negative-do not show statistically significant DR4 differences.

One further person was found to have developed classical RA. This individual was seropositive by all four RF tests when first seen, and had probable RA.

Table 9 Follow up of the individual with probable $R A$ who developed classical $R A$

\begin{tabular}{|c|c|c|}
\hline & \multicolumn{2}{|l|}{ Case 4} \\
\hline & $\begin{array}{l}\text { Ist assessment: } \\
\text { probable } R A\end{array}$ & $\begin{array}{l}\text { 2nd assessment: } \\
\text { classical } R A\end{array}$ \\
\hline \multicolumn{3}{|l|}{$R F$ tests } \\
\hline RAHA & $1 / 640$ & $1 / 640$ \\
\hline IgG RF & 11.45 & $6 \cdot 26$ \\
\hline SCAT & $1 / 512$ & $1 / 256$ \\
\hline Latex & Positive & Positive \\
\hline
\end{tabular}

"Case 4: interval between assessments 26 months, non-blood relative of proband.
Onset of symptoms had been three months before $\infty$ the first assessment. Details of this individual appear in Table 9.

\section{Discussion}

These results suggest that the assays for RF differ in their specificity and sensitivity. This may have arisen from the use of different solid phases, antigens, concentration of antigen on the solid phase, and $\stackrel{\infty}{\circ}$ different ways of quantifying the results. In the RAHA test covalent binding of rabbit IgG to sheep red blood cells allows more IgG to be fixed than is the case with the SCAT where specific antisheep red blood cell antibody is used. Antibodies detected by these tests could be to any part of the rabbit IgG, and a different orientation on the surface could expose different antigens. The latex test employs human IgG coated onto latex particles by passive adherence. The IgG RF test has only human Fc fragments as antigen, thereby avoiding reactivity with the Fab portion of IgG.

RF assays have proved the most useful serological tests in RA. Any role they may have in the onset or $\dot{\delta}$ maintenance of arthritis, or on the pattern of joint $₹$ involvement, remains obscure. It remains to be o defined whether they are involved in the pathogenesis of RA or are produced in response to other changes brought about by RA. Some evidence exists in the case of bacterial endocarditis that immune or complexes are detectable first, followed by rheuma- $N$ toid factors, ${ }^{10}$ which may suggest that rheumatoid $\underset{\mathrm{N}}{\mathrm{N}}$ factor was produced in response to immune com- 0 plexes. The concentration of both $\operatorname{IgM}^{11}$ and $\operatorname{IgG}^{12}$ rheumatoid factors broadly correlates with disease $\frac{0}{\mathbb{D}}$ activity and this may suggest a pathological role. The particular IgG RF method used in this study $T$ was found to correlate better with disease activity than any other blood test in a recent study of RA. ${ }^{13}$ Stronger association of IgG rheumatoid factor with $\stackrel{\odot}{\triangleright}$ disease activity might have suggested that $\operatorname{IgG}_{0}$ 
rheumatoid factor was pathologically more significant than IgM rheumatoid factor. In this study IgG RF and IgM RF were usually positive in the same individuals. IgG RF was not positive in the majority of IgM negative RA sufferers. If rheumatoid factor seropositivity were inherited then it would be expected that RA cases in a family would be uniformly seropositive or seronegative and that false positives would be more frequent in close relatives of seropositive probands. The families in this study have not been consistently seropositive or negative and the false positives do not cluster to the probands. This therefore provides good evidence that rheumatoid factor is not an inherited component of RA in these families.

Previous reports have suggested that only seropositive RA associates with HLA-DR4, ${ }^{14-16}$ and one report has shown association of DR4 with high titre seropositivity. ${ }^{17}$ Other authors disagree, ${ }^{18}$ and DR4 has not been found in association with non-RA seropositivity. ${ }^{19}{ }^{20}$ HLA-DR4 did not show association with non-RA seropositivity in this population and does not show association with high titre seropositivity in the RA group. The association of DR4 with RA in these families was not therefore through association with seropositivity.

There may be differences between seropositive and seronegative RA in HLA association and pattern of joint involvement, but these remain to be substantiated. Griffin $e a^{21}$ failed to reproduce the findings of Burns and Calin. ${ }^{3}$ It is not possible to subdivide RA according to seropositivity by any measure of rheumatoid factor without great overlap of severity, erosiveness, and clinical disease. A recent report studying joint replacement surgery found no evidence of a difference between seropositive and seronegative RA. ${ }^{22}$ It is therefore convenient to regard them as different expressions of the same disease.

The follow up study of individuals with false positive rheumatoid factor tests showed that rheumatoid factor positivity did not uniformly predict the onset of RA over a two year period. The finding of four individuals who had developed classical or definite RA (three from the false positive group and one from the probable RA group) in a population of 175 over a two year period showed a very high incidence of RA and implies that family members were indeed at increased risk of developing RA. The observation that one of these individuals was not a blood relative illustrates that this increased risk may not be entirely inherited. An estimate of the expected incidence of RA in a population of 175 over two years is approximately 0.2 cases (assuming $2 \%$ prevalence being achieved over a 20 year onset period). All cases who developed definite RA were RF positive before the onset of symptoms. The observation that in three of the four new cases of RA the IgG RF index was falling suggests that IgG RF may be involved in the onset of RA.

Only IgG rheumatoid factor and the latex assay predicted all new definite RA cases, and no cases of definite RA occurred in the RF negative control group. Nine false positives had on follow up become RF negative, and therefore the risk of RA appeared to be greater in persistently RF positive individuals. The increased risk of developing RA in the false positive group was mainly in DR4 positive individuals.

\section{References}

1 Aho K, Palosuo T, Raunio V, Puska A, Aromaa A, Salonen J T. When does rheumatoid disease start? Arthritis Rheum 1985; 28: 485-9.

2 Bardin T, Legrand L, Naveau B, et al. HLA antigens and seronegative rheumatoid arthritis. Ann Rheum Dis 1985; 44: 50-3.

3 Burns $T M$, Calin $A$. The hand radiograph as a diagnostic discriminant between seropositive and seronegative rheumatoid arthritis: a controlled study. Ann Rheum Dis 1983; 42: 605-12.

4 Lawrence J S, Ball J. Genetic studies on rheumatoid arthritis. Ann Rheum Dis 1958; 17: 160-8.

5 O'Sullivan J B, Cathcart E S, Bolzan J A. Diagnostic criteria and the incidence of rheumatoid arthritis in Sudbury. In: Bennett P, Wood P, eds. Population studies of rheumatic diseases. Amsterdam: Excerpta Medica, 1968: 109.

6 Ropes M W, Bennett G A, Cobb S, Jacox R, Jessar R A. The ARA criteria for rheumatoid arthritis. Bull Rheum Dis 1958; 9: 175-6.

7 Walker D J, Griffiths M, Dewar P, et al. Association of MHC antigens with susceptibility to and severity of rheumatoid arthritis in multicase families. Ann Rheum Dis 1985; 44: 519-25.

8 Powell R J, Leyland A M, Pound J D, Bossingham D H. An improved assay for IgG rheumatoid factor: its value in the diagnosis of rheumatoid arthritis. $J$ Rheumatol 1985; 12: 427-31.

9 Lawrence J S. Appendix in rheumatism in populations. London: Heinemann, 1977: 525-6.

10 Carson D A, Bayer A S, Eisenberg R A, Lawrance S, Theofilopoulos A. IgG rheumatoid factor in subacute bacterial endocarditis. Relation to IgM rheumatoid factor and circulating immune complexes. Clin Exp Immunol 1978; 31: 100-3.

11 Rose H M, Ragan C, Pearce E, Lipman M O. Differential agglutination of normal and sensitised sheep erythrocytes by sera of patients with rheumatoid arthritis. Proc Soc Exp Biol Med 1948; 68: 1-6.

12 Allen C, Elson C J, Scott D G I, Bacon P A, Bucknall R C. IgG antiglobulins in rheumatoid arthritis and other arthritides: relationship with clinical features and other parameters. Ann Rheum Dis 1981; 40: 127-31.

13 Rudge S R, Pound J D, Bossingham D H, Powell R J. Class specific rheumatoid factors in rheumatoid arthritis: response to chrysotherapy and relationship to disease activity. $J$ Rheumatol 1985; 12: 432-6.

14 Roitt I M, Corbett M, Festenstein H, et al. HLA-DRw4 and prognosis in rheumatoid arthritis. Lancet 1978; i: 990.

15 Dobloug J H, Forre O, Kass E, Thorsby E. HLA antigens and rheumatoid arthritis (association of HLA-DRw4 and IgM rheumatoid factor production). Arthritis Rheum 1980; 23: 309-13. 
16 Queiros M V, Sancho M R H, Caetano J M. HLA-DR4 antigen and IgM rheumatoid factors. J Rheumatol 1982; 9: 370-3.

17 Stastny P. Rheumatoid arthritis. In: Terasaki P I, ed. Histocompatibility testing. Los Angeles: UCLA Press, 1980: 681-6.

18 Panayi G S, Wooley P H, Batchelor J R. HLA-DR4 and rheumatoid arthritis. Lancet 1979; i: 730.

19 Engleman E G, Sponzilly E F, Batey M E, Ramcharan S, McDevitt H O. Mixed lymphocyte reaction in healthy women with rheumatoid factor. Arthritis Rheum 1978; 21: 690-3.
20 Gran J T, Husby G, Thorsby E. The prevalence of HLA-DR4 and HLA-DR3 in healthy persons with rheumatoid factor. Scand J Rheumatol 1985; 14: 79-82.

21 Griffin J, Celinska E, Panayi G S, Gibson T, Grahame R. A radiological study of seronegative and seropositive rheumatoid arthritis. Br J Rheumatol 1985; 24: 92.

22 Bradlow A, Mowat A G. Comparison of reconstructive orthopaedic surgery in patients with seropositive and seronegative rheumatoid arthritis. Br J Rheumatol 1985; 24: 179-86. 